\title{
El español hablado en Valencia. Interferencia lingüística y enseñanza de la lengua
}

\author{
JORGE ROSELLÓ VERDEGUER \\ Universitat de València \\ Jorge.Rosello@uv.es \\ DAVID GIMÉNEZ FOLQUÉS \\ Universitat de València \\ David.Gimenez-Folques@uv.es
}

Resumen. Todas las lenguas muestran variación, tanto desde el punto de vista geográfico como social, y su aprendizaje siempre se produce a través de una de sus variedades geográficas. Hay zonas en que el español convive con otras lenguas, y esto le da una serie de características especiales que el profesor de español como lengua extranjera debe conocer y explicar a sus alumnos. En este trabajo, analizamos algunas interferencias lingüísticas que se producen entre español y valenciano, variedad del catalán que se habla en Valencia, y proponemos algunas actividades didácticas para su aprovechamiento en las clases de ELE.

Palabras clave. Variación, dialectos, interferencia lingüística, enseñanza.

Abstract. All languages show variation both from a geographical and a social point of view, and its learning is always produced through one of its geographical varieties. There are areas where the Spanish language coexist with other languages, and this gives it a series of special features which the teachers of Spanish as a foreign language must know and explain to his/her students. In this paper, we analyze some linguistic interferences which are produced between Spanish and Valencian -a variety of Catalan which is spoken in Valencia- and, finally, we propose some teaching activities to be used in ELE classes.

Key words: variation, dialect, linguistic interference, teaching. 


\section{Introducción}

Como han puesto de relieve muchos estudiosos, el español es una lengua homogénea que hace posible el entendimiento entre hablantes procedentes de muy diferentes lugares. Ello no es incompatible, como ocurre con otras lenguas, con la existencia de variedades, tanto geográficas como sociales. Respecto a las primeras, Moreno Fernández (2000) distingue diversas zonas o áreas:

- Español del Caribe, representado, por ejemplo, por los usos de San Juan de Puerto Rico, La Habana o Santo Domingo.

- Español de México y Centroamérica, representado, por ejemplo, por los usos de la ciudad de México y otras ciudades y territorios significativos.

- Español de los Andes, representado, por ejemplo, por los usos de Bogotá, La Paz o Lima.

- Español de la Plata y del Chaco, representado por los usos de Buenos Aires, de Montevideo o de Asunción.

- Español de Chile, representado por los usos de Santiago.

A esas cinco áreas se añaden tres más para el español de España:

- Español castellano, representado por los usos de ciudades como Madrid o Burgos.

- Español de Andalucía, representado por los usos de Sevilla, Málaga o Granada.

- Español de Canarias: Las Palmas o Santa Cruz de Tenerife.

Sin embargo, no se aporta mucha información sobre aquellos territorios en los que el español convive con otras lenguas. Para el caso del español europeo, hay varias comunidades en España en las que está reconocida oficialmente otra lengua. ¿Presenta el español en estas zonas variedades o particularidades? Indudablemente, sí. ¿Deben ser tenidas en cuenta? A juzgar por lo que los especialistas manifiestan sobre la enseñanza de lenguas, es muy conveniente que los profesores de español como segunda lengua o lengua extranjera dispongan de una formación adecuada sobre la realidad dialectal de la lengua que enseñan. Debe saber que determinado giro es utilizado especialmente en la zona o que esa palabra se suele decir de otra manera. Así, un valenciano cuando habla español difícilmente diría «un niño chico», «la pernera del pantalón es estrecha», o «un paquete de patatas fritas». A un valenciano, seguramente, le suena mejor «yo de ti no lo haría» que "yo que tú no lo haría», y si le sorprende la lluvia sin paraguas y sin posibilidad de ponerse a resguardo, antes exclamará «¡me estoy chopando!» que «jestoy empapado!».

De manera que, volviendo al inicio, la pregunta que debemos formularnos es «¿Qué español enseñar?». Sin duda, se nos dirá que el español estándar. Pero esto también encierra una trampa, ya que ninguno de nosotros posee la «variedad estándar». Nuestra variedad está condicionada por toda una serie de rasgos fonéticos, morfosintácticos y léxicos. Pero es evidente que los grandes difusores de la lengua, esto es, la enseñanza y los medios de comunicación, necesitan un modelo que les sirva de guía.

Así pues (Figura 1), partimos de una lengua estándar, pero la enseñamos nosotros, que tenemos una serie de rasgos lingüísticos, un idiolecto en términos sociolingüisticos, que intentamos, en la medida de los posible, acomodar al estándar. Pero, lógicamente, esos 
rasgos van a aflorar en cuanto nos relajemos un poco, por lo que al final damos con un estándar "sui géneris". Como señala Moreno Fernández (2014), "es decididamente preferible utilizar como modelo o referencia el español de la región hispánica propia, la más cercana o con la que se tiene una mayor relación o afinidad".

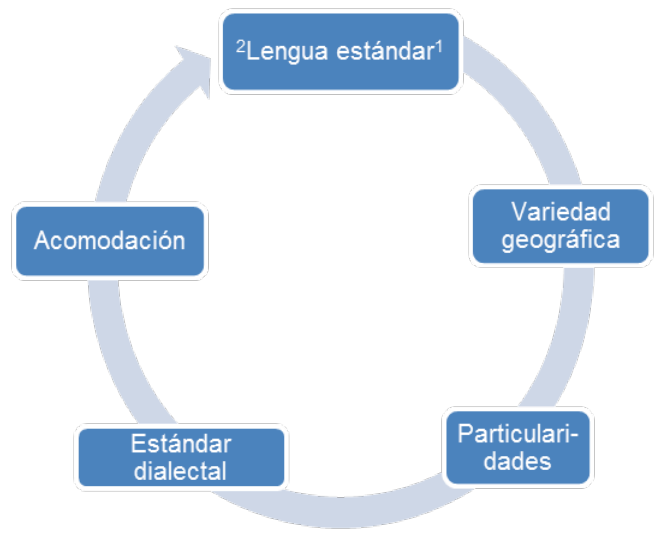

Figura 1

De esta manera, pensamos que el profesorado que enseña español en Valencia debe conocer la variedad dialectal que se habla en esta zona de España, puesto que el estudiante que recorra sus calles y hable con sus gentes se va a encontrar con muchos giros que no son habituales en el español estándar y que son utilizados con normalidad por los hablantes valencianos.

\section{El contacto lingüístico}

El contacto entre lenguas es un hecho común y habitual en muchas regiones y países. Una de las consecuencias que produce este hecho son las interferencias lingüísticas. El concepto de interferencia ha sido muy debatido dentro del ámbito de la sociolingüística, pues es difícil determinar con precisión sus parámetros. Weinreich fue de los primeros autores en formular este concepto, que parece indicar, como su propio nombre indica, una desviación o una influencia de una lengua hacia otra. No obstante, el concepto de interferencia no es el único al que ha dado el lugar los fenómenos derivados de situaciones de lenguas en contacto, ya que es muy habitual en sociolingüística distinguir entre interferencia, convergencia, préstamo y cambio de código.

Weinreich (1968) distingue dos tipos de interferencia: a) interferencias del habla, que derivan del conocimiento por parte del hablante bilingüe de una segunda lengua, y b) interferencias de la lengua, que serían aquellas que, a través del uso continuado en el habla, formarían ya parte del sistema lingüístico. El problema está en determinar con precisión cuándo un fenómeno concreto forma parte del sistema, ya que se necesitarían estudios cuantitativos para verificarlo. Blas Arroyo (2004) señala algunos de estos fenómenos para el español de Valencia: determinados usos de hacer (ique olor hace!, qué hacen en $T V$, ¿nos hacemos un café?); la neutralización formal de las categorías adverbial (abajo) y preposicional (bajo); el empleo de un que átono al comienzo de las oraciones interrogativas absolutas; ciertos fenómenos de convergencia como la concordancia en impersonales con haber (habian flores en el jardín); la reducción a 
estructuras nominales de sintagmas preposicionales con valor temporal (tengo el carné siete años), etc.

Algunos autores evitan el término interferencia, por las connotaciones negativas que ha ido adquiriendo el término (ataque a las normas del sistema, error, desvío, etc.), y prefieren usar otro más neutro, transferencia. No obstante, muchos estudios sobre bilingüismo y contacto de lenguas usan también el término convergencia, ya que, según señala Serrano (2011: 334), no presupone la existencia de cuestiones incorrectas o agramaticales $\mathrm{y}$, además, da cuenta de las condiciones en las que un elemento transferido se puede adaptar a la lengua receptora. En este sentido, la convergencia indicaría la tendencia a igualar estructuralmente dos lenguas que están en contacto.

El otro concepto al que hacíamos referencia es el de préstamo, aunque hay que advertir que, en realidad, todo préstamo es originariamente una interferencia, ya que se trata de un elemento extraño de una lengua que se incorpora a otra con la que está en contacto. En la actualidad, según indica Gómez Molina (2004: 292), no existe unanimidad ni en la delimitación conceptual de interferencia y préstamo ni en las denominaciones terminológicas, puesto que hay autores que prefieren hablar solo de préstamos puntuales o espontáneos, préstamos en transición y préstamos estables o consolidados, mientras que otros mantienen la diferenciación, pero relacionando la interferencia con situaciones de desplazamiento de una de las lenguas y el préstamo en caso de mantenimiento de ambas.

Cualquiera que sea el término que se acuñe, lo cierto es que todas estas interferencias están muy presenten en la conversación coloquial del español hablado en Valencia, y aquí las reseñamos para darlas a conocer en las clases de ELE. Sabemos que la presencia de la interferencia supone un desvío de la norma de la lengua española, y que el profesorado debe primar lo correcto sobre lo incorrecto. Pero es también cierto que muchos de estos desvíos de la norma tienen orígenes dialectales, arraigan más en algunos territorios y acaban consolidándose en ellos. Es el caso del leísmo en muchas zonas de Castilla (no olvidemos que muchos usos leístas están justificados etimológicamente) o la personalización del verbo haber en Valencia y en territorios americanos. El conocimiento de la realidad lingüística y cultural de la zona donde se está inmerso es fundamental para el estudiante que está aprendiendo el idioma.

\section{El área metropolitana de Valencia}

El español del que damos cuenta aquí es, principalmente, el utilizado en la zona metropolitana de Valencia, en donde se habla español y valenciano, variedad dialectal del catalán. Elegimos esta zona tanto por el número de habitantes (es la tercera más poblada de España) como por su importancia social y económica dentro de la Comunidad. La zona metropolitana de Valencia está formada por cuarenta y cuatro municipios (Figura 2), resultado de una realidad económica y sociológica incuestionable, y cuenta con 1.545.564 habitantes. La mayoría proviene del mismo municipio $(40,5 \%)$ o de la provincia de Valencia $(24,8 \%)$. De otras comunidades españolas proviene el 19,5\% y del extranjero, un $13,3 \%{ }^{1}$.

\footnotetext{
${ }^{1}$ Datos extraídos de la oficina estadística del Ayuntamiento de Valencia.
} 
Por otra parte, Valencia es un destino muy solicitado por estudiantes Erasmus de toda Europa. En efecto, en el documento «Top 100 higher education institutions receiving Erasmus students in 2009/10», la Universitat de Valencia aparece como la segunda universidad europea que más estudiantes Erasmus recibió durante el curso 2009-2010 (1770 estudiantes), y la Universistat Politècncia de València, la tercera (1638), solo superadas por la Universidad de Granada $(1862)^{2}$.

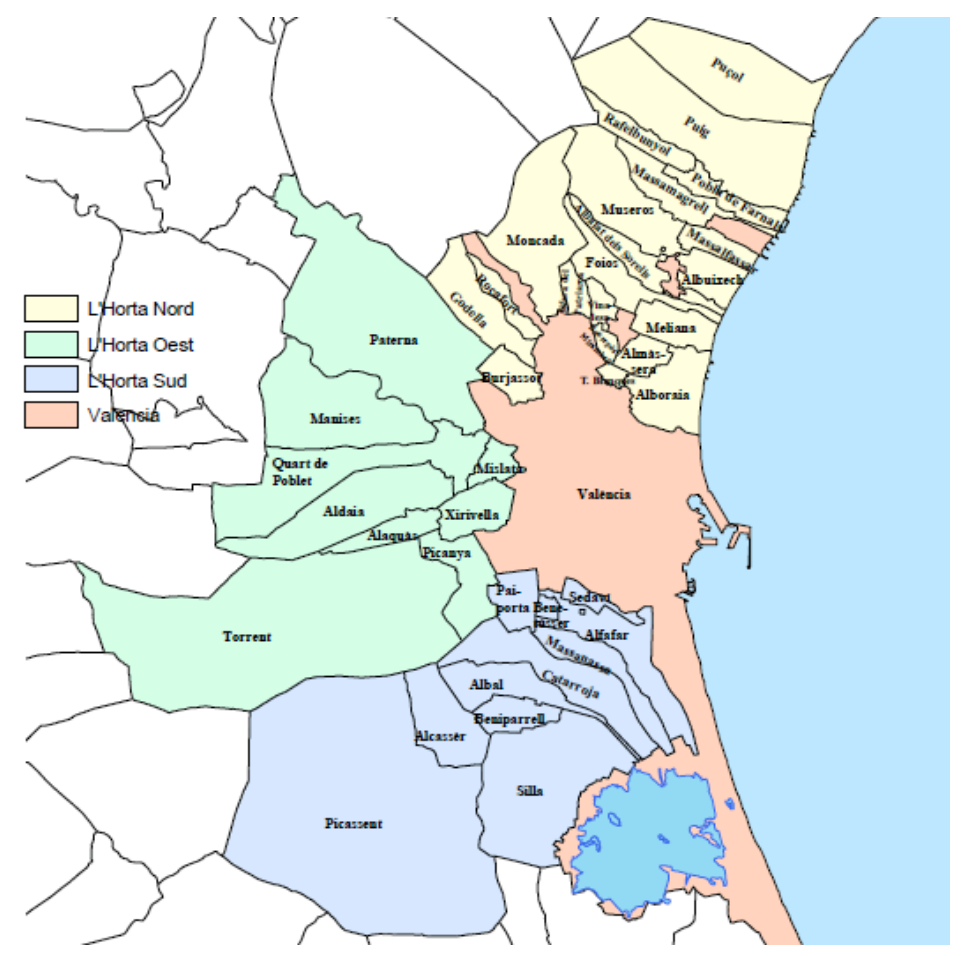

Figura 2

Para mostrar las características del español hablado en Valencia nos basamos en diversos corpus: el PRESEEA-Valencia (PRESEVAL), el corpus Val.Es.Co., el CORPES... Como se sabe, un corpus es una recopilación de textos, actualmente muchos de ellos en soporte electrónico, que son representativos de la lengua que se va a estudiar y que son fuente de datos para investigaciones lingüísticas. Los corpus, como pone de manifiesto Cruz Piñol (2012: 35), permiten disponer de muestras reales de la lengua en uso, poner a prueba y comprobar las teorías lingüísticas o las intuiciones y obtener información cuantitativa y, por tanto, verificable. En nuestro caso, los ejemplos extraídos de los diversos corpus nos sirven para fundamentar todos aquellos rasgos del español coloquial hablado en Valencia y para proponer con ellos aplicaciones didácticas de utilidad en las clases de ELE. Entendemos que con todas esas características podemos hablar de un «modelo de español» hablado por los valencianos y que el conocimiento de esos rasgos es de utilidad para desenvolverse en la zona de aprendizaje.

\footnotetext{
${ }^{2}$ Fuente: «Top 100 higher education institutions receiving Erasmus students in 2009/10». http://www.upv.es/noticias-upv/documentos/4674a.pdf
} 
Así pues, vamos a dar cuenta de toda una serie de rasgos fonéticos, morfosintácticos y léxicos que pueden ser tratados en las clases de ELE y que presentan particularidades en el español hablado en Valencia.

\section{Muestras del español hablado en Valencia para su uso en ELE}

\subsection{Nivel fónico}

En el nivel fónico, como señala Briz (2004: 125), uno de los rasgos más evidentes del contacto lingüístico entre ambas lenguas lo constituye la prosodia, en concreto, la entonación y los cambios acentuales [Kámbiaméla]. Destacan, igualmente, algunos fenómenos fonéticos como el de la pronunciación labiodental de la grafía $v$, el ensordecimiento de la consonante sonora /d/ en posición final (Madrit), las aberturas vocálicas, etc.

Podemos oír algunos de estos rasgos (aberturas vocálicas, entonación...) y otros (monoptongaciones, como vinticinco; sonorización de consonantes sordas, como /s/, etc.) en la siguiente muestra, extraída del corpus PRESEVAL (entrevista 50). http://www.uv.es/preseval/ppal.htm (Figura 3).

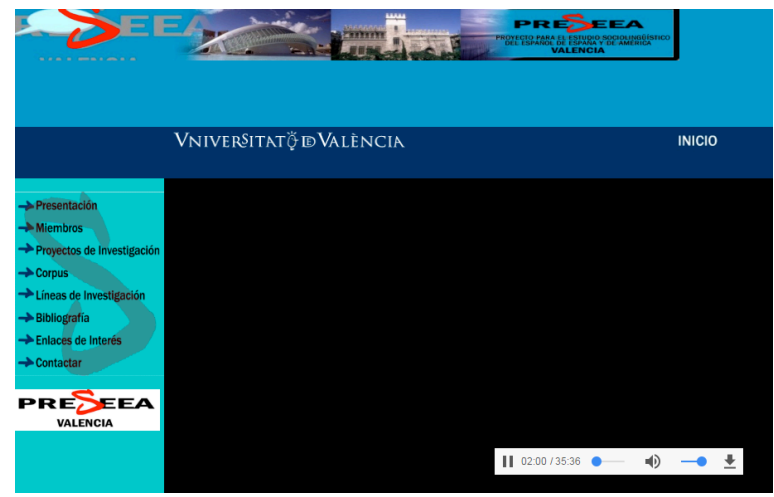

Figura 3

\subsection{Nivel morfosintáctico}

En cuanto a los rasgos morfológicos y sintácticos, debemos hacer mencionar, en primer lugar, la confusión de las preposiciones en / con cuando tienen valor de compañía o instrumental, como en (1-2):

(1) pos la fideuàl/la fideuà que/ a mí/ también/me sale muy buena A: ¿cómo [la hace?]

B: $\quad$ [yo l(a) hago] en caldo/ de rapel/ y cabeza dee-d(e) esto

(2) ... pues esta casa hoy en los metros cuadrados que tiene la casal pues igual a lo mejor valía diez millones o doce/ no lo sé

(PRESEVAL)

Observamos, igualmente, la presencia abundante de diminutivos con terminación et(e) y eta (3-5):

(3) para venir a trabajar veníamos con el treneet entonces yy- y eso/ nos juntá(b)amos los cuatro amigos

(4) A: claro que sí

(PRESEVAL)

D: $y$ después [un heladete $\uparrow$ ] 
(5) C: ... porque les va a ellos/ que son de Caudiel/ el pueblo de la $\S$

$\mathrm{J}:$

$\S m i e r-\S$

C:

§caqueta (RISAS) y de Utiel

(Val.Es.Co)

También la confusión entre la preposición bajo y el adverbio abajo (6):

(6) la plaza aquella que hicieron nueva/ que hay un aparcamiento bajo/ alli quitaron unn par de calles

(PRESEVAL)

En cuanto a la morfología verbal, encontramos la personalización sistemática del verbo haber (7-8), fenómeno estudiado con detalle por Gómez Molina (2013):

(7) ponían los carros/todos/ no habían barreras como ahora// habían carros/// yy unas vigas así a las ruedas para que no se saliera el toro//

(8) y vi/ con una lucecita indicaba-para los señores que habían alli/ que habian venido de Madrid

(PRESEVAL)

Por último, podemos mencionar el uso de interjecciones peculiares, caso de che, interjección que denota asombro o sorpresa (9):

(9) [no tengo] ningún seis/ el cuatro/ ;che! si no tengo ningún cuatro/

¡che!/ pero ¿qué es?

(Val.Es.Co)

Fórmulas de tratamiento propias de Valencia, como es el caso de nano, un apelativo coloquial para llamar la atención de un amigo o compañero (10):

(10) A: habláis poco ¿eh?

C: ¿para qué? §

B: $\quad \S$ ¿qué quieres que hablemos $\downarrow$ nano $\uparrow ?$

(Val.Es.Co)

Y, también, ciertas fórmulas de despida o cierre, au, interjección para despedirse o para zanjar algún asunto (11):

(11) J: me huele mal eso// (RISAS)

C: pon íguel y ;au!

\subsection{Nivel léxico}

(Val.Es.Co).

El apartado léxico representa uno de los ámbitos donde más ejemplos podemos encontrar del contacto lingüístico. Esta interferencia la observaremos, principalmente, en hablantes bilingües. A partir de los corpus que hemos trabajado, podemos señalar que entre voces y expresiones hemos encontrado, aproximadamente, unos cien ejemplos de influencia valenciana. Así mismo, los ámbitos más prolíficos en este sentido lo conforman la gastronomía, la festividad y el hogar. Observemos en primer lugar algunos ejemplos gastronómicos:

(12) C: pues mira si tiene/ tiene cigalas/ dos o tres// lo menos/ o cuatro cigalas/ y tiene gambas/ y tiene clóchinas/y tiene $\rightarrow$ / y tiene cangrejos $\rightarrow$ y tiene TROCITOS de todo $\uparrow$

(13) ...iba a decirle/ aquí en Valencia es muy típico los fartons/ entonces también me gusta poner al medio/ y rosquilletas/ toodo lo típico valenciano/ porque cuantas más cosas [pones...] 
(14) ...ee laa- últimamente me gusta mucho hacer fideuás/ y me gusta muchísimo el rape/ el rape con almendritas

(15) J: noo// que no saben ir por el mundo ¡coño!

M: nena/ suca, suca (3',)

$\mathrm{J}$ : hombree/hay cosas que no se pueden aguantar/ porque hay cosas que a lo mejor/ oye/// claro igual pero

$$
\text { C: yy/// cordero } \uparrow / \text { torraico } \uparrow \text { ¿o no degusta a ti el cordero? } \S
$$

(Val.Es.Co).

Otro de los ámbitos donde podemos encontrar un gran número de voces, producto de este contacto, sería el festivo, sobre todo en lo que se refiere al evento de las Fallas. También aparecen otras festividades, aunque en menor medida, como sería el caso de la Tomatina:

(17) Un recorrido por la historia de las fallas a través de la casi centenaria revista Pensat i fet es el objeto de la exposición.

(18) El Ninot indultat, que tiene el privilegio de no ser quemado en la noche de San José.

(19) Y, por si no hubiera bastantes, seguimos inventándolas. Ya ven: la Tomatina de Buñol es un jolgorio colectivo que apenas si cuenta con 50 años de historia.

(CORPES).

\section{Muestra de propuesta didáctica}

\subsection{El contexto académico}

Hasta ahora hemos visto rasgos fónicos, morfosintácticos y léxicos del español hablado en Valencia, variante que proponemos llevar al aula de E/LE; pero no simplemente con listados de fenómenos que puedan ser aprendidos de memoria y olvidados por el estudiante, sino mediante actividades lúdicas y didácticas que permitan una adaptación de nivel curricular y de participación por parte del receptor de la misma. Para llevar a cabo estas actividades, sería conveniente enseñar a nuestros alumnos, previamente, el contexto del español hablado en Valencia. Es decir, les hablaríamos de las características que hemos señalado anteriormente. A continuación, estaríamos en disposición de introducir actividades como las que proponemos a continuación ${ }^{3}$.

\subsection{Texto gastronómico}

A partir del siguiente texto proponemos que los estudiantes extraigan aquellos fenómenos morfosintácticos o léxicos que pertenezcan al español hablado en Valencia. En niveles iniciales marcaremos el fenómeno y lo trabajaremos conjuntamente con ellos, y en niveles superiores les pediremos que directamente los busquen y analicen ${ }^{4}$ :

\footnotetext{
${ }^{3}$ Nuestro objetivo no es otro que el de realizar una mera propuesta de actividades que podrían ser tomadas como modelo para el desarrollo posterior de una unidad didáctica que cubra los distintos niveles lingüísticos.

${ }^{4}$ Texto extraído de: http://canalcocina.es/actualidad/especiales/la-cocina-valenciana-platos-tipicos-de-lacomunidad-valenciana.
} 
Uno de los entrantes valencianos más comunes se llama Esgarraet, Especant o Esguellat (en función de la localidad). Es una ensalada de verduras asadas, bacalao en salazón, ajo y aceite de oliva. Dependiendo de cada zona, se usan unas u otras hortalizas, aunque las básicas son la berenjena y el pimiento rojo. Las cocas, las empanadillas y las rosquilletas son otros de los aperitivos más comunes en todos los hogares y panaderías valencianas.

Pero sin duda, el plato que genera más admiración y controversia al mismo tiempo es la famosa Paella. ¿Pero qué ingredientes lleva la Paella tradicional valenciana? La Paella tiene muchas variantes dependiendo de la zona donde se prepare, como Paella de verduras, de marisco, de carne, mixta... Aunque la más popular es la Paella de carne y ésta sería la que podría acuñarse como "Paella valenciana". Los ingredientes principales con los que se prepara son: arroz rendondo, pollo, conejo, garrofó, judías y romero fresco. Un término asociado a la Paella es el socarrat y muchos son los adeptos a este efecto agarrado del arroz en la Paella, que se consigue justo al final de la cocción.

Otro plato popular y reconocido es la Fideuà, más propio de las zonas costeras valencianas. La Fideuà se elabora como la Paella, pero sus ingredientes son los fideos, el pescado y el marisco fresco de cada lonja local.

Os dejamos diferentes recetas tradicionales valencianas del programa Hoy Cocina el Alcalde, donde la caravana de Canal Cocina hace parada en Sueca, Guardamar del Segura, Elche y Denia para poner a prueba la maestría entre fogones de sus alcaldes y descubrir los secretos de los platos típicos de la cocina valenciana, de los cuales os dejamos algunos ejemplos:

Paella de Sueca

Arroz meloso con dorada, langostinos, sepia y ñoras

Arroz con conejo, pollo y caracoles

Arroz a banda

Fideuà de Gandia

¿Pero existen platos tradicionales valencianos sin arroz? "Che, claro" como afirmaría un valenciano. Destacamos El all i pebre, propio de la Albufera valenciana, elaborado con ajo, pimentón y anguila del mismo parque natural, el Guisado de sepia, la Olleta de Castellón de la plana y la Olleta alicantina.

Valencia tiene muchos productos con denominación de origen, ejemplo de ello son las clóchinas valencianas (clotxines valencianes), unos mejillones sabrosos y con carácter mediterráneo, las alcachofas de Benircarló, los dátiles de Elche, las ñoras de Guardamar, la miel de la Marina Alta, las naranjas valencianas, el arroz de los campos de la Albufera, vinos D.O Utiel-Requena o los famosos langostinos de Vinaroz.

Para familiarizarse con productos locales valencianos, os proponemos una receta con langostinos de Vinaroz: Langostinos de Vinaròs con arroz venere y crema de ajo, una versión de nuestros Blogueros cocineros del blog Gastronomía y Cía.

Figura 4

\subsection{Texto oral}

En esta ocasión vamos a trabajar un texto auditivo. De esta manera la actividad no solo nos ofrece la oportunidad de extraer fenómenos morfosintácticos y léxicos, sino también nos permite mostrar aquellos fenómenos fónicos fruto del contacto lingüístico. Esta última parte fónica la trabajaríamos, principalmente, en niveles superiores, dada la dificultad que conlleva este tipo de análisis: 
Completa los espacios en los textos a partir de la siguiente audición. A continuación, analiza con el profesor los cambios vocálicos y consonánticos que se producen en este texto oral:

Pista 1: http://www.uv.es/preseval/ppal.htm (audición 50) ${ }^{5}$

Yo nací en Valencia, estuve viviendo en Valencia hasta los cuatro años, a los cuatro años pasé a vivir a Godella y estuve allí hasta los vinti... vinticuatro años y luego volví aquí, volví a Valencia y desde entonces vivo en Valencia.

Mi hija quiere hacer arquitectura. O va a Valencia o se va a Madrid o a Barcelona. Que se venga aquí, con los primos hermanos. Ya no hablo con la familia.

Bueno pues ni me acuerdo ya, ni me acuerdo, porque en aquella época, pues jugábamos con una pelota de trapo y a tirar piedras a los árboles, que se suele decir.

Cuando nacieron los hijos busqué, busqué por ahí por Godella encontrar algo para ellos, porque como yo me he cria(d)o siempre así. De pequeño en Godella y después pues no sé.

Figura 5

\section{Conclusiones}

Como hemos podido observar, estamos ante una variante del español que cuenta con una serie de rasgos morfosintácticos (diminutivos con terminación et(e) y eta, personificación del verbo haber, confusión de preposiciones), fónicos (pronunciación labiodental de la $v$, ensordecimiento de /d/ en posición final, aberturas vocálicas) y léxicos (voces gastronómicas y festivas, expresiones propias, etc.) que son reconocibles en el territorio de la Comunidad Valenciana y, específicamente, en la ciudad de Valencia.

Por otro lado, si pretendemos enseñar esta variante del español en clase de E/LE, se aconseja hacerlo mediante actividades que puedan ser útiles y que ayuden al alumno a reflexionar sobre estos rasgos propios, como hemos mostrado en las actividades propuestas (crear propuestas didácticas a partir de textos escritos y orales). De esta manera, el alumno procesará de forma significativa el material que le estamos enseñando.

En conclusión, para trabajar la lengua española en clase de E/LE hay que tener en cuenta su condición de idioma heterogéneo, compuesto de múltiples variantes, todas ellas válidas para cualquier contexto educativo.

\section{Bibliografía}

Blas Arroyo, J.L. (1993). La interferencia lingüística en Valencia (dirección cataláncastellano). Castellón: Publicacions de la Universitat Jaume I.

\footnotetext{
${ }^{5}$ Texto extraído de: http://www.uv.es/preseval/ppal.htm (audición 50).
} 
Blas Arroyo, J.L. (2004). Sociolingüistica del español. Madrid: Cátedra.

Blas Arroyo, J. L. (2005). «El español actual en las comunidades del ámbito lingüístico catalán». En Cano Aguilar, R. (ed.), Historia de la lengua española (pp. 1065-1086). España: Ariel.

BRIZ GómEZ, A. (2004). «El castellano en la Comunidad valenciana». Revista Internacional de Lingüistica Iberoamericana II, 2(4), 119-129.

Briz GómEZ, A. y GRUPO Val.Es.Co (2002). Corpus de conversaciones coloquiales. Madrid: Arco/Libros.

CAsanova, E. (1996). «El castellà de València». En Pragmática y gramática del español hablado. Actas del II Simposio sobre análisis del discurso oral (pp. 293-298). Zaragoza: Pórtico.

CRUZ PIÑol, M. (2012). Lingüistica de corpus y enseñanza del español como 2/L. Madrid: Arco/Libros.

Gómez MolinA, J.R. (2004). «Consecuencias del contacto lingüístico», en A. Briz Gómez y Grupo Val.Es.Co. ¿Cómo se comenta un texto coloquial? (pp. 287-313). Barcelona: Ariel.

Gómez Molina, J.R. (coord.) (2001). El español hablado en Valencia. Materiales para su estudio I. Nivel sociocultural alto. Anejo XLVI de Cuadernos de Filología. Valencia: Universitat de València.

Gómez Molina, J. R. (coord.) (2005). El español hablado en Valencia. Materiales para su estudio II. Nivel sociocultural medio. Anejo LVIII de Cuadernos de Filología. Valencia: Universitat de València.

Gómez Molina, J. R. (coord.) (2007). El español hablado en Valencia. Materiales para su estudio III. Nivel sociocultural bajo. Anejo LXI de Cuadernos de Filología. Valencia: Universitat de València.

Gómez Molina, J.R. (coord.) (2013). El español de Valencia. Estudio sociolingüístico. Berna: Peter Lang.

Moreno Fernández, F. (2000). Qué español enseñar. Madrid: Arco/Libros

Moreno Fernández, F. (2014). «Español de España-Español de América. Mitos y realidades de su enseñanza». V Congreso Internacional de FIAPE. Recuperado de: https://www.academia.edu/17129150/Espa\%C3\%B1ol_de_Espa\%C3\%B1a_Espa\%C3\%B1ol_de_Am\%C3\%A9rica._Mitos_y_realidades_de_su_ense $\% \bar{C} 3 \%$ B 1 anza

SINNER, C. y A. WESCH (eds.) (2008). El castellano en tierras de habla catalana. Madrid: Iberoamericana-Vervuert.

SERrAnO, M.J. (2011). Sociolingüística. Barcelona: Ediciones del Serbal.

Weinreich, U., W. LABOV y I. Herzog (1968): «Empirical Foundations for a Theory of Language Change». En W.P. Lehmann y Y. Malkiel (eds.), Direction for Historical Linguistics (pp. 97-195). Austin, University of Texas Press. 